\title{
Prevalence of Low Back Pain among Adolescent Students in a Nigerian Urban Community
}

\author{
Akinpelu, A.O. ${ }^{1}$, Oyewole, 0.0. ${ }^{2}$, Hammed, G.O. ${ }^{1}$, Gbiri, C. A. ${ }^{3}$ \\ ${ }^{1}$ Department of Physiotherapy, College of Medicine, University of Ibadan, Ibadan, Nigeria \\ ${ }^{2}$ Department of Physiotherapy, Olabisi Onabanjo University Teaching Hospital, Sagamu, Nigeria \\ ${ }^{3}$ Department of Physiotherapy, College of Medicine, University of Lagos, Nigeria \\ Correspondence
}

Olufemi O. Oyewole, Department of Physiotherapy, Olabisi Onabanjo University Teaching Hospital, PMB 2001,Sagamu, Ogun State, Nigeria・oyewoleye@yahoo.co.uk

\section{SUMMARY}

This school-based survey was aimed at determining the prevalence of low-back pain (LBP) among adolescent students of selected secondary schools in Ibadan, Nigeria.

Nine hundred secondary schools students, comprising 415 boys and 485 girls, with age range $12-17$ years were surveyed. They were required to complete a self-developed, three-part items questionnaire which collected information on socio-demographic characteristics, history and intensity of low back pain, factors predisposing to low back pain, and activity limitations suffered because of low back pain.

The 12 -month and point prevalence of LBP among participants were $40.7 \%$ and $12.9 \%$ respectively. For boys the 12 -month prevalence of LBP was $41.7 \%$ and for girls it was $39.8 \%$. The point prevalence of LBP was $14.2 \%$ for girls and $11.3 \%$ for boys. Most of the participants had their first LBP experience at 10-15 years, with a peak at 12-14 years. The LBP experienced by most participants was of short duration and only a few episodes, suggesting non-chronicity. Over $50 \%$ of the participants were involved in activities that make them frequently bend at the waist.

The findings of this survey suggest that LBP is fairly prevalent among Nigerian adolescents. Health education on LBP prevention will help reduce its incidence in this population.

KEYWORDS: low back pain, prevalence, adolescent students, Nigeria

\section{INTRODUCTION}

Low-back pain (LBP) is frequent among school children and adolescents (Wedderkopp et al, 2001; Masiero et al, 2008). Previous studies have reported the prevalence of low back pain in adults and adolescents. A prevalence of $64.8 \%$ was reported for Danish adolescents, $57 \%$ for Norwegian adolescents, $46.2 \%$ for Spanish adolescents, $30.2 \%$ for German adolescents, $18 \%$ for Finnish adolescents, $7.5 \%$ for Dutch adolescents, $40.2 \%$ for American adolescents, 17.4-20.5\% for Italian adolescents, $57.8 \%$ for Kuwaiti adolescents, $28.4 \%$ for Tunisian adolescents, and $13.5 \%$ for Mozambican adolescents (Taimela et al, 1997; Jones et al, 2004; Prista et al, 2004; Sjolie, 2004; Shehab et al, 2004; Bejia et al, 2005; Roth-Isigkeit et al, 2005; Diepenmaat et al, 2006; Mohseni-Bandpei et al, 2006; Masiero et al, 2008; Skoffer and Foldspang, 2008; Pellisé et al, 2009). In Nigeria, 59\% life time prevalence and $17 \%$ point prevalence were reported in adolescents (Ayanniyi et al, 2011). A range of $40-44 \%$ prevalence was reported for Nigerian adults in rural and urban communities (Omokhodion, 2002; 2004).

Several factors have been reported to be associated with increased prevalence of LBP. The occurrence increases with age, especially in the early teen years (Taimela et al, 
1997; Wedderkopp et al, 2005). Risk factors associated with the development of low back pain include rapid growth, smoking, tight quadriceps femoris, tight hamstrings, and working activities during the school year (Feldman et al, 2001). Frequent computer-related activities have been reported as an independent risk factor for neck/shoulder pain and LBP (Sjolie, 2004; Hakala et al, 2006). Daily backpack carrying has also been identified as a frequent cause of musculoskeletal discomfort for adolescents (Chiang et al, 2006). Sporting activities such as jogging, handball, gymnastics and riding were associated with an increased period prevalence risk, while swimming correlated with a reduced LBP occurrence in point prevalence (Skoffer and Foldspang, 2008). Similarly, LBP was inversely associated with time spent on physical activity, in particular with regular walking or bicycling (Sjolie, 2004).

Depressive symptoms were reported to be associated with neck/shoulder pain, low back pain, and arm pain (Diepenmaat et al, 2006). Emotional problems, conduct problems, chronic headaches, abdominal pain, sore throats, and daytime tiredness were strongly associated with LBP (Watson et al, 2003). A significant association was also observed for gender (female), positive family history of LBP, and absence of sports activity as risk factors for LBP (Masiero et al, 2008). There was a strong association between health status and LBP (Hestbaek et al, 2006; Mattila et al, 2008).

Studies on prevalence of low back pain in Nigerian adolescents are few. Such information is needed as the predisposing factors differ from nation to nation. It is therefore the aim of this study to assess the prevalence of LBP in Nigerian secondary school adolescents, find out if gender differences exist in the prevalence, and determine the age of peak prevalence.

\section{METHODS}

One thousand adolescents, aged 12-17, from 10 selected secondary schools within Ibadan North Local Government Area participated in this cross-sectional descriptive survey. Data were collected using a self-developed, three part questionnaire with closed-ended questions. Section A collected information on socio-demographic data, section $\mathrm{B}$ sought information on history of low back pain (LBP), intensity of pain using the ordinal scale (mild to extremely severe), and factors predisposing to low back pain, while section $\mathrm{C}$ collected information on activity limitations suffered because of LBP.

Prior to the distribution of the questionnaire, the content validity of the questionnaire was assessed among ten experienced physiotherapists (on individual basis) working in the orthopaedic ward and out-patient physiotherapy clinic. The questionnaire was also pretested on 10 students who reported that the questions were not ambiguous, free of jargons and easily understood. After detailed explanation of the nature and purpose of the study by one of the authors, consenting students (100 from each school in various classes) completed copies of the questionnaire which were distributed and collected with the help of the class teachers. Data were analysed using descriptive statistics.

\section{RESULTS}

Out of the 1000 copies of the questionnaire distributed among the participants, 900 were duly completed and returned, giving a $90 \%$ response rate. Three hundred and sixty-six participants $(40.7 \%)$ reported that they had experienced LBP while $534(59.3 \%)$ participants indicated that they had never experienced pain in their lower back (table 1). The 12-month prevalence of LBP increased with age, from $31.9 \%$ at age 12 to $46.2 \%$ at age 17 ; and it was higher among male than female participants (table 1).

Table 1. 12-month and point prevalence of low back pain among participants by age and gender

\begin{tabular}{lrrrrr}
\hline & & \multicolumn{5}{c}{ Prevalence } \\
\cline { 3 - 6 } Age & & \multicolumn{2}{c}{ 12-month } & \multicolumn{3}{c}{ Point } \\
\hline 12 & $\mathrm{n}$ & $\mathrm{n}$ & $\%$ & $\mathrm{n}$ & $\%$ \\
13 & 69 & 22 & 31.9 & 5 & 7.2 \\
14 & 110 & 40 & 36.3 & 12 & 10.9 \\
15 & 204 & 74 & 36.3 & 25 & 12.3 \\
16 & 231 & 98 & 42.4 & 24 & 12.6 \\
17 & 154 & 71 & 46.1 & 24 & 15.6 \\
Gender & 132 & 61 & 46.2 & 21 & 15.9 \\
Male & 415 & 173 & 41.7 & 47 & 11.3 \\
Female & 485 & 193 & 39.8 & 69 & 14.2 \\
All & 900 & 366 & 40.7 & 116 & 12.9 \\
\hline
\end{tabular}

Out of the $366(40.7 \%)$ participants who reported having experienced LBP, $334(91.3 \%)$ indicated the intensity of the pain during the last episode (table 2). More 
Prevalence of Low Back Pain Among Adolescent Students in a Nigerian Urban Community

than half of the participants rated their pain as either moderate $(n=152,41.5 \%)$ or mild $(n=91,24.9 \%)$. The majority $(74 \%)$ of those who reported experiencing LBP indicated that the LBP lasted $\leq 2$ weeks while $17.8 \%$ had it for $\geq 3$ weeks. At the time of the study, 116 participants had LBP, giving a point prevalence of $12.9 \%$ (table 1). The point prevalence of LBP increased from $7.2 \%$ in 12 year olds to $15.9 \%$ in 17 year olds, and it was higher in female than male adolescents (table 1). The frequently reported pain intensities by participants who reported LBP as at the time of the survey were moderate pain $(42.2 \%)$, followed by mild pain $(23.2 \%)$. Extremely severe pain was the least reported intensity (table 2 ).

Table 2. 12-month and point prevalence of pain intensity

\begin{tabular}{lcccc}
\hline Pain intensity & \multicolumn{4}{c}{ Prevalence } \\
\cline { 2 - 5 } & \multicolumn{2}{c}{ 12-month } & Point \\
\cline { 2 - 5 } & 24.9 & $(91)$ & 23.2 & $(27)$ \\
\hline Mild & 41.5 & $(152)$ & 42.2 & $(49)$ \\
Moderate & 13.4 & $(49)$ & 17.2 & $(20)$ \\
Severe & 7.1 & $(26)$ & 11.2 & $(13)$ \\
Very severe & 4.4 & $(16)$ & 6.2 & $(7)$ \\
Extremely severe & 8.7 & $(32)$ & 0 & $(0)$ \\
Not reported & &
\end{tabular}

Three hundred and sixty one $(98.6 \%)$ out of the 366 adolescents who reported LBP experience indicated the age at which they first experienced LBP (table 3). Most of those who had experienced LBP $(88.5 \%)$ first experienced it between the ages of 10 and 15 . The peak age at which LBP was first experienced was 12 to 14 years. The majority of the respondents had experienced LBP only once $(42.8 \%)$ while the others had experienced it 2-5 times $(38.8 \%)$ and $15.8 \%$ had had six or more occurrences (table 3 ).

All 900 participants that were involved in the study indicated their level of involvement in eight different activities indicated in the questionnaire. The questions asked were to elicit the predisposing factors to LBP. Over $50 \%$ (498) were very often and often involved in all the activities (table 4). Among these, $79 \%$ of the male and $85.3 \%$ of the female participants were very often and often involved in sweeping floors using short brooms. Higher proportions of male respondents were found very often involved in five of the activities than female respondents.
Table 3. Age at which low back pain was first experienced

\begin{tabular}{lcc}
\hline Age (years) & $\mathrm{n}$ & $\%$ \\
\hline 2 & 1 & 0.3 \\
3 & 1 & 0.3 \\
4 & 4 & 1.2 \\
5 & 2 & 0.5 \\
6 & 5 & 1.4 \\
7 & 1 & 0.3 \\
8 & 4 & 1.2 \\
9 & 6 & 1.6 \\
10 & 49 & 13.4 \\
11 & 24 & 6.6 \\
12 & 73 & 19.9 \\
13 & 84 & 23.0 \\
14 & 65 & 17.8 \\
15 & 29 & 7.9 \\
16 & 9 & 2.5 \\
17 & 8 & 2.2 \\
\hline
\end{tabular}

Table 4. Frequency distribution of participants' involvement in predisposing factors of low back pain by gender

\begin{tabular}{|c|c|c|c|c|c|}
\hline \multirow[t]{2}{*}{$\begin{array}{l}\text { Predisposing } \\
\text { factors }\end{array}$} & & $\begin{array}{l}\text { Very } \\
\text { often }\end{array}$ & Often & Seldom & Not at al \\
\hline & & $f(\%)$ & $\mathrm{f}(\%)$ & $f(\%)$ & $f(\%)$ \\
\hline \multirow{2}{*}{$\begin{array}{l}\text { Lifting/carrying of } \\
\text { heavy objects }\end{array}$} & M & $152(36.6)$ & $106(25.5)$ & $93(22.4)$ & $64(15.5)$ \\
\hline & $\mathrm{F}$ & $161(33.2)$ & $163(33.6)$ & $90(18.5)$ & $71(14.6)$ \\
\hline \multirow{2}{*}{$\begin{array}{l}\text { Sitting on chair or } \\
\text { bench without back } \\
\text { rest }\end{array}$} & M & $111(26.8)$ & $103(24.8)$ & $161(38.8)$ & $40(9.6)$ \\
\hline & $\mathrm{F}$ & $123(25.4)$ & $131(27)$ & $159(32.8)$ & $72(14.9)$ \\
\hline \multirow{2}{*}{$\begin{array}{l}\text { Sweeping floor } \\
\text { using broom }\end{array}$} & M & $196(47.2)$ & $132(31.8)$ & $51(12.3)$ & $36(8.7)$ \\
\hline & $\mathrm{F}$ & $231(47.6)$ & $183(37.7)$ & $39(8)$ & $42(8.7)$ \\
\hline \multirow{2}{*}{$\begin{array}{l}\text { Fetching of water } \\
\text { from well }\end{array}$} & M & $102(24.6)$ & $122(29.4)$ & $145(34.9)$ & $46(11.1)$ \\
\hline & $\mathrm{F}$ & $153(31.5)$ & $121(25)$ & $168(34.6)$ & $43(8.9)$ \\
\hline \multirow{2}{*}{$\begin{array}{l}\text { Washing bending } \\
\text { down }\end{array}$} & M & $147(35.4)$ & $103(24.8)$ & $106(25.5)$ & $59(14.2)$ \\
\hline & $\mathrm{F}$ & $162(33.4)$ & $190(39.2)$ & $107(22.1)$ & $26(5.4)$ \\
\hline \multirow{2}{*}{$\begin{array}{l}\text { Standing for } 15 \\
\text { minutes or more }\end{array}$} & M & $112(27.0)$ & $106(25.5)$ & $102(24.6)$ & $95(22.9)$ \\
\hline & $\mathrm{F}$ & $128(26.4)$ & $122(25.2)$ & $118(24.3)$ & $117(24.1)$ \\
\hline \multirow{2}{*}{$\begin{array}{l}\text { Sitting on a chair } \\
\text { with back slouched }\end{array}$} & M & $115(27.7)$ & $105(25.3)$ & $100(24.1)$ & $95(22.9)$ \\
\hline & $\mathrm{F}$ & $155(32)$ & $130(26.8)$ & $110(22.7)$ & $90(18.6)$ \\
\hline Sleeping on & M & $133(32.1)$ & $104(25.1)$ & $103(24.8)$ & $75(18.1)$ \\
\hline sagging & $F$ & $144(29.7)$ & $163(33.6)$ & $103(21.1)$ & \\
\hline mattr & & & & & $75(15.5)$ \\
\hline
\end{tabular}

Key: $M=$ male, $F=$ female 


\section{DISCUSSION}

The recorded 12-month and point prevalence of $40.7 \%$ and $12.9 \%$ respectively of LBP found among the adolescents involved in this study suggest that LBP is fairly common among Nigerian adolescents residing in Ibadan. These prevalence rates were different from those reported for adolescent populations in some other countries. The 12month prevalence of LBP reported in this study was higher than those reported for Flemish adolescents (24.7\%), Tunisian adolescents $(28.4 \%)$, and adolescents in Germany (30.2\%) (Bejia et al, 2005; Roth-Isigkeit et al, 2005; Staes et al, 2007). The 12-month prevalence was however the same with that found in American adolescents (40.2\%) (Jones et al, 2004). The 12-month prevalence in this study was found to be lower than that reported in Kuwaiti adolescents (57.8\%) (Shehab et al, 2004) and Danish adolescents (64.8\%) (Skoffer and Foldspang, 2008).

The average point prevalence $(12.9 \%)$ observed in the present sample is actually higher than the $10.1 \%$ reported among Danish adolescents and lower than that reported for American adolescents (15.5\%) (Leboeuf-Yde and Kyvik, 1998; Jones et al, 2004). The differences in prevalence might be due to variations in the definition of low back pain and slight differences in the age of participants. Some of the previous studies included primary school pupils who were lower in age (Jones et al, 2004; Shehab et al, 2004; Skoffer and Foldspang, 2008) and some included the lower thoracic region in their definition of low back (Leboeuf-Yde and Kyvik, 1998).

The findings from this study also show that 12-month and point prevalences increase with age, agreeing with previous research (Taimela et al, 1997; Jones et al, 2004; Wedderkopp et al, 2005; Ayanniyi et al, 2011). This might imply that the higher the age the higher the chances of LBP. This study observed higher 12-month prevalence in male adolescents, which was contrary to a previous study from Nigeria which found no gender difference in the prevalence of back pain (Ayanniyi et al, 2011). The findings were however similar to those in another study in which gender difference was observed in Nigerian urban adult population with men reporting a higher prevalence (Omokhodion, 2004). However, this observation was at variance with previous cross-sectional studies that showed a greater female predisposition to low back pain (Shehab et al, 2004; Diepenmaat et al, 2006; Pellisé et al, 2009) The reason for male preponderance in this study is unclear but it may be attributed to the fact that male adolescents were often involved in activities that predisposed them to low back pain. The outcome of this study also revealed that the majority of participants in this environment first experienced LBP between the ages of 12 and 14. This finding is in agreement with that of Shehab et al (2004) and Leboeuf-Yde and Kyvik (1998) who found the peak age onset of LBP in Kuwait and Denmark to be between 13 and 14 years.

The short duration of LBP of less than a week, mild and moderate pain intensity as well as few number of episodes reported by the adolescents in this study suggest that the pain experienced was non-chronic. This suggests that the pre-adolescent or adolescent period is the appropriate time to educate people on what can be done to prevent LBP and its chronicity. The results also showed that many of the adolescents were often involved in activities that made them bend their trunk, thus predisposing them to LBP. Again this indicates the need for back health education for adolescents.

Research into children's health and health behaviour and the factors that influence them is essential for the development of effective health education and health promotion policy, programmes and practice targeted at young people (Currie et al, 2000). It appears from the evidence that there is a strong case for the introduction of the concept of back health into the curriculum or as part of the healthy school initiative. Given the multifactorial causes of LBP, several health education strategies within the school setting have the potential to reduce the incidence of LBP. Linking to the WHO healthy schools initiative seems plausible. Key areas would be:

1. promoting a healthy environment

2. health education

3. providing opportunities for physical education and recreation, and

4. offering programmes for social support (Jones et al, 2004)

Health education strategies in schools could include advice along the lines of adult back-schools regarding back health and ergonomic advice. Preliminary studies have suggested that education about back health may be effective in reducing the incidence of low-back pain in children (Balague et al, 1996; Cardon et al, 2001). 
Prevalence of Low Back Pain Among Adolescent Students in a Nigerian Urban Community

\section{CONCLUSION}

The findings of this study suggest that low back pain is prevalent among adolescent students in Ibadan North Local Government and that its prevalence increases with age. There is a need to include back health education in the school curriculum to prevent or reduce the incidence of low back pain in this population.

\section{References}

Ayanniyi, O, Mbada, C.E, Muolokwu, C.A. 2011. Prevalence and profile of back pain in Nigerian adolescents. Med Princ Pract 20:368-373

Balague, F., Nordin, M., Dutoit, G. and Waldburger, M. 1996. Primary prevention, education and low back pain among school children. Bulletin of the Hospital for Joint Diseases 55: 130-134.

Bejia, I., Abid, N., Salem, K.B., Letaief, M., Younes, M., Touzi, M. and Bergaoui, N. 2005. Low back pain in a cohort of 622 Tunisian schoolchildren and adolescents: an epidemiological study. European Spine Journal 14(4):331-336

Cardon, G., Bourdeaudhuij, I.D., and Clercq, D.D. 2001. Generalization of back education principles by elementary school children: evaluation with a practical test and a candid camera observation. Acta Paediatrica 90: 143-150.

Chiang, H., Jacobs, K., Orsmond, G. 2006. Gender-age environmental associates of middle school students' low back pain. Work: A Journal of Prevention, Assessment and Rehabilitation 26(1): 19-28.

Currie, C., Hurrelmann, K., Settertobulte, W., Smith, R. and Todd, J. 2000. Health and health behaviour among young people. WHO policy series: Health Policy for Children and Adolescents Issue 1. WHO, Copenhagen.

Diepenmaat, A.C.M., van der Wal, M.F., de Vet H.C.W. and Hirasing, R.A. 2006. Neck/Shoulder, Low Back, and Arm Pain in Relation to Computer Use, Physical Activity, Stress, and Depression among Dutch Adolescents. Pediatrics 117: 412-416

Feldman, D.E., Shrier, I., Rossignol, M. and Abenhaim, L. 2001. Risk Factors for the Development of Low Back Pain in Adolescence. American Journal of Epidemiology 154(1): 30-36

Hakala, P.T., Rimpelä, A.H., Saarni, L.A. and Salminen, J.J. 2006. Frequent computer-related activities increase the risk of neck-shoulder and low back pain in adolescents. The European Journal of Public Health 16(5): 536-541

Hestbaek, L., Leboeuf-Yde, C., and Kyvik, K.O. 2006. Is comorbidity in adolescence a predictor for adult low back pain? A prospective study of a young population. BMC Musculoskelet. Disord 7: 29.
Jones, M. A., Stratton, G., Reilly, T. and Unnithan, V. B. 2004. A school-based survey of recurrent non-specific low-back pain prevalence and consequences in children. Health Education Research 19(3): 284-289

Leboeuf-Yde, C. and Kyvik, K.O. 1998. At what age does low back pain become a problem? A study of 24,424 individuals aged 12-41 years. Spine 23: 228-234.

Masiero, S., Carraro, E., Celia, A., Sarto, D., Ermani, M. 2008. Prevalence of nonspecific low back pain in schoolchildren aged between 13 and 15 years. Acta Padiatrica 97(2): 212 - 216.

Mattila, V.M, Sahi, T., Jormanainen, V., and Pihlajamäki, H. 2008. Low back pain and its risk indicators: a survey of 7,040 Finnish male conscripts. Eur Spine J 17(1): 64-69.

Mohseni-Bandpei, M.A., Bagehri-Nessami, M. and ShayestehAzar, M. 2006. Non-specific low back pain in 5000 iranian schoolchildren: an epidemiological study. Annals of the Rheumatic Diseases 65(Suppl 2): 241.

Omokhodion, F.O. 2002. Low back pain in a rural community in south west Nigeria. WAJM 2(2):87-90.

Omokhodion, F.O. 2004. Low back pain in an urban population in south west Nigeria. Tropical Doctor 34: 17-20

Pellisé, F., Balagué, F., Rajmil, L., Cedraschi, C., Aguirre, M., Fontecha, C.G., Pasarín, M., Ferrer, M. 2009. Prevalence of low back pain and its effect on health-related quality of life in adolescents. Arch Pediatr Adolesc Med 163(1):65-71

Prista, A., Balagué, F., Nordin, M. and Skovron, M. L. 2004. Low back pain in Mozambican adolescents. European Spine Journal 13(4):341-345.

Roth-Isigkeit, A., Thyen, U., Stöven, H., Schwarzenberger, J., and Schmucker, P. 2005. Pain among children and adolescents: restrictions in daily living and triggering factors. Pediatrics 115(2):e152-e162.

Shehab, D., Al-Jarallah, K., Al-Ghareeb, F., Sanaseeri, S., AlFadhli, M., Habeeb, S. 2004. Is low-back pain prevalent among Kuwaiti children and adolescents? Med Princ Pract 13:142-146.

Sjolie, A.N. 2004. Associations between activities and low back pain in adolescents. Scandinavian Journal of Medicine \& Science in Sports 14(6): 352 - 359.

Skoffer, B. and Foldspang, A. 2008. Physical activity and low-back pain in schoolchildren. Eur Spine J 17(3): 373-379.

Staes, F., Stappaerts, K., Lesaffre, E., Vertommen, H. 2007. Low back pain in Flemish adolescents and the role of perceived social support and effect on the perception of back pain. Acta Padiatrica 92(4):444 - 451.

Taimela, S., Kujala, U.M., Salminen, J.J., Viljanen, T. 1997. The prevalence of low back pain among children and adolescents. A nationwide, cohort-based questionnaire survey in Finland. Spine 22(10):1132-6.

Watson, K.D., Papageorgiou, A.C., Jones, G.T., Taylor, S., Symmons, D.P.M., Silman, A.J., Macfarlane, G.J. 2003. 
Low back pain in schoolchildren: the role of mechanical and psychosocial factors. Archives of Disease in Childhood 88:1217.

Wedderkopp, N., Andersen, L.B., Froberg, K., and Leboeuf-Yde, C. 2005. Back pain reporting in young girls appears to be puberty-related. BMC Musculoskelet Disord 6: 52.
Wedderkopp, N., Leboeuf-Yde, C., Andersen, L.B., Froberg K., Hansen, H.S. 2001. Back pain reporting pattern in a Danish population-based sample of children and adolescents. Spine 26:1879-1883 . 